\title{
Cross-national prevalence and risk factors for suicidal ideation, plans and attempts
}

Matthew K. Nock, Guilherme Borges, Evelyn J. Bromet, Jordi Alonso, Matthias Angermeyer, Annette Beautrais, Ronny Bruffaerts, Wai Tat Chiu, Giovanni de Girolamo, Semyon Gluzman, Ron de Graaf, Oye Gureje, Josep Maria Haro, Yueqin Huang, Elie Karam, Ronald C. Kessler, Jean Pierre Lepine, Daphna Levinson, Maria Elena Medina-Mora, Yutaka Ono, José Posada-Villa and David Williams

\section{Background}

Suicide is a leading cause of death worldwide; however, the prevalence and risk factors for the immediate precursors to suicide - suicidal ideation, plans and attempts - are not wellknown, especially in low- and middle-income countries.

\section{Aims}

To report on the prevalence and risk factors for suicidal behaviours across 17 countries.

\section{Method}

A total of 84850 adults were interviewed regarding suicidal behaviours and socio-demographic and psychiatric risk factors.

\section{Results}

The cross-national lifetime prevalence of suicidal ideation, plans, and attempts is 9.2\% (s.e.=0.1), 3.1\% (s.e.=0.1), and $2.7 \%$ (s.e.=0.1). Across all countries, $60 \%$ of transitions from ideation to plan and attempt occur within the first year after ideation onset. Consistent cross-national risk factors included being female, younger, less educated, unmarried and having a mental disorder. Interestingly, the strongest diagnostic risk factors were mood disorders in high-income countries but impulse control disorders in low- and middle-income countries.

\section{Conclusion}

There is cross-national variability in the prevalence of suicidal behaviours, but strong consistency in the characteristics and risk factors for these behaviours. These findings have significant implications for the prediction and prevention of suicidal behaviours.

\section{Declaration of interests}

None. Funding detailed in Acknowledgements.
Suicide is among the leading causes of death worldwide. ${ }^{1}$ Yet, basic data on the prevalence and risk factors for suicide and its immediate precursors - suicidal ideation, plans and attempts are unavailable in many countries around the world, particularly those that are less developed. ${ }^{2}$ Most studies of suicidal thoughts and behaviours (hereafter 'suicidal behaviours') have been conducted within individual Western, high-income countries ${ }^{3-6}$ and it is not known whether prevalence estimates and risk factors identified in such studies generalise beyond these countries. Recent studies in several low- and middle-income countries such as China and India suggest the occurrence of suicidal behaviours may differ markedly from high-income countries. For instance, this work suggests that gender and the presence of mental disorders play less of a role in the occurrence of suicidal behaviours in low- and middle-income countries. ${ }^{7,8}$ Data on suicidal behaviours collected cross-nationally would provide a unique opportunity to evaluate the consistency of prevalence estimates and risk factors for these important outcomes, and would greatly inform research, policy, and treatment efforts more broadly aimed at understanding and preventing suicide around the world. ${ }^{1,9}$

The purpose of the current study was to estimate the crossnational prevalence of suicidal behaviours and to examine risk factors for these outcomes using data from the World Health Organization (WHO) World Mental Health (WMH) Survey Initiative. ${ }^{10}$ Several studies have provided valuable information about suicidal behaviours across several countries., ${ }^{5,11,12}$ The current study extends prior work by conducting a more thorough examination of suicidal behaviours, using more consistent assessment methods across sites, and represents the largest, most representative examination of suicidal behaviours ever conducted.

\section{Method}

\section{Respondent samples}

The WMH surveys were carried out in 17 countries: Africa (Nigeria, South Africa); the Americas (Colombia, Mexico, USA); Asia and the Pacific (Japan, New Zealand, Beijing and Shanghai in the People's Republic of China); Europe (Belgium, France, Germany, Italy, The Netherlands, Spain, Ukraine); ${ }^{13}$ and the Middle East (Israel, Lebanon). The World Bank ${ }^{14}$ classifies China, Colombia, Lebanon, Mexico, Nigeria, South Africa and Ukraine as less developed or low- and middle-income countries, and all other survey countries as high-income countries. All surveys were conducted face-to-face by trained lay interviewers among multi-stage household probability samples (described in the online Table DS1). The total sample size was 84850 , with individual country sample sizes ranging from 2372 in The Netherlands to 12992 in New Zealand. The weighted average response rate across all countries was $71.1 \%$.

\section{Procedures}

All respondents completed a Part I interview that contained core diagnostic assessments, including the assessment of suicidal behaviours. All Part I respondents who met criteria for any disorder and a subsample of approximately $25 \%$ of the remainder of the respondents were administered a Part II interview that assessed potential correlates and disorders of secondary interest ( $n=48427)$. Data were weighted to adjust for this differential sampling of Part II respondents, differential probabilities of 
selection within households, and to match samples to population socio-demographic distributions.

Standardised interviewer training procedures, WHO translation protocols for all study materials, and quality control procedures for interviewer and data accuracy that have been consistently employed across all WMH countries are described in more detail elsewhere. ${ }^{10,15,16}$ Informed consent was obtained before beginning interviews in all countries. Procedures for obtaining informed consent and protecting individuals were approved and monitored for compliance by the institutional review boards of organisations coordinating surveys in each country.

\section{Measures of suicidal behaviours}

Suicidal ideation, plans and attempts were assessed using Version 3.0 of the WHO Composite International Diagnostic Interview (CIDI) ${ }^{16}$ The computer-assisted WMH-CIDI (for Windows) was used in countries where it was financially and logistically possible to do so; elsewhere, the paper-and-pencil version was used. Based on evidence that reports of such potentially embarrassing behaviours are higher in self-administered than intervieweradministered surveys, ${ }^{17}$ these questions were printed in a selfadministered booklet and referred to by letter (e.g. 'Did experience C ever happen to you?'; in booklet, 'C=You attempted suicide'). If the respondent was unable to read, the interviewer read these items aloud (19.5\% of all instances). Interviews assessed the lifetime presence and age-of-onset of each outcome.

\section{Risk factors for suicidal behaviours}

Interviews also examined three sets of risk factors for suicidal behaviours: socio-demographics, characteristics of suicidal behaviours and temporally prior DSM-IV mental disorders (i.e. those with an onset prior to the first onset of suicidal ideation). The socio-demographic factors included gender, age/cohort, education, employment history, and marital history. Characteristics of suicidal behaviours included age-of-onset of ideation, time since onset of ideation, presence of a suicide plan and time since onset of plan. Respondent disorders were assessed using the WHO CIDI. ${ }^{16}$ The assessment included DSM-IV mood, anxiety, impulse control and substance use disorders. Prior studies using clinical reappraisal interviews have found CIDI diagnoses to have good concordance with blinded diagnoses based on the Structured Clinical Interview for DSM-IV ${ }^{18}$ in probability subsamples of respondents from the surveys in France, Italy, Spain and the USA. $^{19,20}$

\section{Statistical analysis}

Cross-tabulations were used to estimate lifetime prevalence of suicidal ideation, plans and attempts. Discrete-time survival analysis with person-year as the unit of analysis and including both stable (e.g. gender) and time-varying (e.g. marital history) covariates ${ }^{21}$ was used to study retrospectively assessed risk factors for the first onset of each suicidal behaviour. Discrete-time survival analysis uses each year of life of each respondent as a separate observation, so that a sample of 100000 respondents with an average age of 30 years would be treated as 3 million separate records. Each record is coded for the respondent's stable characteristics (e.g. gender), the respondent's age at the time of the observational record (e.g. the 20th year of a respondent's life who was age 45 years at the time of interview), values on the time-varying predictors as of that year of life (e.g. whether or not the respondent was still a student, had ever been married, and had ever been employed as of age 20), and values on the outcomes as of that year (e.g. whether or not the respondent had ever made a suicide attempt and, if so, whether this was the year of the respondent's first lifetime attempt). The data file was analysed to compare person-years for all respondents that had never had the outcome of interest $v$. the year of first onset of the outcome using a logistic regression modelling approach and controlling for person-year (i.e. age at the time of the observational record) as well as for the predictors. Logistic regression coefficients were converted to odds ratios (ORs) for ease of interpretation and $95 \%$ confidence intervals (CIs) are also reported and have been adjusted for design effects. Continuous variables were divided into categories to minimise effects of extreme values. Standard errors (s.e.) and significance tests were estimated using the Taylor series method ${ }^{22}$ using SUDAAN software $^{23}$ (for UNIX) to adjust for the effects of weighting and clustering. Multivariate significance was evaluated using Wald $\chi^{2}$-tests based on design-corrected coefficient variance-covariance matrices. Statistical significance was evaluated using two-tailed 0.05-level tests.

\section{Results}

\section{Prevalence}

The estimated lifetime prevalence of suicidal ideation, plan and attempt in the overall cross-national sample is $9.2 \%$ (s.e. $=0.1$ ), $3.1 \%$ (s.e. $=0.1$ ) and $2.7 \%$ (s.e. $=0.1$ ), respectively (online Table DS2). Among suicide ideators, the conditional probability of ever making a suicide plan is $33.6 \%$ (s.e. $=0.7$ ) and of ever making a suicide attempt is $29.0 \%$ (s.e. $=0.6$ ). The probability of attempt among ideators with a plan is $56.0 \%$ (s.e. $=1.2$ ) but only $15.4 \%$ (s.e. $=0.6)$ among those without a plan (online Table DS3).

Within-country prevalence estimates show substantial variability, with the cross-national estimate outside the 95\% CI in 13 of the 17 countries for suicidal ideation, and 12 of the 17 for suicide plans and attempts. Prevalence estimates in low- and middle-income countries are similar to those in high-income countries for: suicidal ideation $(3.1-12.4 \%$ v. 3.0-15.9\% respectively), suicide plan $(0.9-4.1 \% \quad v .0 .7-5.6 \%$ respectively) and suicide attempt $(0.7-4.7 \%$ v. $0.5-5.0 \%$ respectively). Although prevalence estimates varied cross-nationally, the conditional probability of suicide plan and attempt among ideators is more consistent across countries, with the cross-national estimate outside the $95 \%$ CI in only 5 of the 17 countries for plans, 7 of 17 countries for attempts, 9 of 17 countries for unplanned attempts, and 4 of 17 countries for planned attempts.

\section{Socio-demographic factors}

In the cross-national sample, risk of each suicidal behaviour is significantly related to being female, younger age, having fewer years of formal education, and before ever being married (Table $1)$. The ORs of these predictors are fairly modest in magnitude $(\mathrm{OR}=1.3-3.1)$ with the exception of age. Age is inversely related to risk of each suicidal behaviour, with ORs increasing as age decreases $(50-64$ years, $\mathrm{OR}=2.6-3.4 ; 35-49$ years, $\mathrm{OR}=4.2-5.6$; 18-34 years, $\mathrm{OR}=9.5-12.4$ ). Employment history is unrelated to suicidal behaviours. Notably, the relations between the sociodemographic risk factors and suicidal behaviours are attenuated when predicting suicide plans and attempts among ideators (Table 2), suggesting the relations between these socio-demographic factors and suicide plans and attempts are due primarily to their association with suicidal ideation.

Within-country findings are very similar to those in the pooled sample. For example, a dominant sign pattern exists for female gender and risk of the three main outcomes of suicidal ideation, plan and attempt (i.e. 47 of the 51 ORs across the 17 separate countries are 1.0 or greater) and $57 \%$ of the within-country 
Table 1 Socio-demographic risk factors for first onset of suicide-related outcomes: pooled analysis ( $n=48$ 427).

\begin{tabular}{|c|c|c|c|c|c|c|}
\hline \multirow[b]{2}{*}{ Socio-demographic factor } & \multicolumn{2}{|c|}{ Ideation } & \multicolumn{2}{|c|}{ Plan } & \multicolumn{2}{|c|}{ Attempt } \\
\hline & OR & $95 \% \mathrm{Cl}$ & OR & $95 \% \mathrm{Cl}$ & OR & $95 \% \mathrm{Cl}$ \\
\hline \multicolumn{7}{|l|}{ Gender } \\
\hline Female & $1.4^{*}$ & 1.3 to 1.4 & $1.4^{*}$ & 1.3 to 1.6 & $1.7 *$ & 1.5 to 1.9 \\
\hline$\chi_{1}^{2}$ & $83.0^{* *}$ & & $41.8^{* *}$ & & $75.7 * *$ & \\
\hline \multicolumn{7}{|l|}{ Age, years ${ }^{a}$} \\
\hline $18-34$ & $9.5^{\star}$ & 8.1 to 11.0 & $10.3^{*}$ & 8.0 to 13.3 & $12.4^{*}$ & 9.1 to 16.8 \\
\hline $35-49$ & $4.2^{*}$ & 3.7 to 4.9 & $4.3^{*}$ & 3.4 to 5.6 & $5.6^{*}$ & 4.1 to 7.5 \\
\hline $50-64$ & $2.6^{*}$ & 2.2 to 3.0 & $2.7^{*}$ & 2.1 to 3.4 & $3.4^{*}$ & 2.4 to 4.7 \\
\hline$\chi_{3}^{2}$ & $1139.6^{* *}$ & & $454.5^{\star *}$ & & 417.0 ** & \\
\hline \multicolumn{7}{|l|}{ Education $^{\mathrm{b}}$} \\
\hline Student & $2.6^{*}$ & 2.2 to 3.0 & $2.5^{\star}$ & 1.9 to 3.3 & $2.6^{*}$ & 2.0 to 3.4 \\
\hline Low & $2.0^{*}$ & 1.8 to 2.3 & $2.0^{*}$ & 1.7 to 2.5 & $3.1^{*}$ & 2.5 to 3.9 \\
\hline Low/medium & $1.3^{*}$ & 1.2 to 1.5 & $1.4^{*}$ & 1.2 to 1.7 & $1.8^{*}$ & 1.4 to 2.3 \\
\hline Medium & $1.4^{*}$ & 1.2 to 1.6 & $1.5^{\star}$ & 1.2 to 1.8 & $1.7^{*}$ & 1.4 to 2.1 \\
\hline$\chi_{4}^{2}$ & $233.4^{* *}$ & & $67.9 * *$ & & $119.1^{* *}$ & \\
\hline \multicolumn{7}{|l|}{ Ever employed } \\
\hline No & 0.9 & 0.8 to 1.0 & 0.9 & 0.7 to 1.1 & 0.9 & 0.7 to 1.1 \\
\hline$\chi_{1}^{2}$ & 2.7 & & 1.6 & & 2.0 & \\
\hline \multicolumn{7}{|l|}{ Ever married } \\
\hline No & $1.3^{*}$ & 1.2 to 1.5 & $1.3^{*}$ & 1.1 to 1.5 & $1.4^{*}$ & 1.2 to 1.7 \\
\hline$\chi_{1}^{2}$ & $40.0 * *$ & & $14.2^{\star *}$ & & $17.9^{* *}$ & \\
\hline $\begin{array}{l}\text { Results are based on multivariate } \\
\text { a. Referent category: } 65+\text { years. } \\
\text { b. Referent category: high educa } \\
{ }^{\star} P<0.005 \text {; }{ }^{*} P<0.01 \text {, two-sided }\end{array}$ & urvival mode & son-year as th & nalysis; se & for a descriptio & hodel contrc & \\
\hline
\end{tabular}

ORs for gender are significant at the 0.05 level. Odds ratios for female gender are always 1.0 or greater for suicidal ideation, and are less than 1.0 in only two instances for suicide plan (Japan 0.9 , Nigeria 0.9) and two instances for attempt (Colombia 0.9, Nigeria 0.8), none being statistically significant. Similarly, the strong relation between age and risk of suicidal behaviours is consistent across 16 of the 17 countries (in Japan the highest risk of each outcome is in the $35-49$ years cohort), with $88 \%$ of the within-country ORs for the youngest cohort significant at the 0.05 level. Results are similar but less consistently significant in within-country analyses for education, employment and marital history given the relatively small effect sizes for these relations.

\section{Characteristics of suicidal behaviours as risk factors}

Suicide ideators within each country were classified into terciles based on age-of-onset of suicidal ideation to examine the relation between age-of-onset and risk of transition from ideation to plans and attempts. Analyses revealed that earlier age-of-onset is significantly associated with greater risk of suicide plan and attempt among those with ideation (Table 2). Importantly, the transition from suicidal ideation to first onset of plan or attempt is extremely elevated within the first year of onset of ideation $(\mathrm{OR}=117.4$ 123.1), and decreases substantially thereafter ( $\mathrm{OR}=1.5-4.4)$. Among ideators, having a suicide plan is associated with a significantly higher risk of making an attempt $(\mathrm{OR}=7.5)$, although the odds of making an unplanned attempt within the first year after onset of ideation are just as high $(\mathrm{OR}=174.6)$ as the odds of making an attempt within the first year after onset of a plan $(\mathrm{OR}=168.4)$. Thus, whether a plan is present or not, the highest risk of suicide attempt is in the first year after onset of ideation.

Examination of age-of-onset curves reveals that across all 17 countries the risk of first onset of suicidal ideation increases sharply during adolescence and young adulthood (online Fig. DS1). These curves separate in the mid-teens to early 20s, with several countries (Japan, New Zealand, USA) showing an earlier increase in risk of suicidal ideation, while other countries have a sharp increase in risk later in life (Israel, Mexico, Spain, Ukraine). Conditional age-of-onset curves show that the rapid transitions from ideation to attempt (online Fig. DS2) occur within the first year of onset of ideation more than $60 \%$ of the time across all 17 countries. The same pattern was observed for the transitions from ideation to plan and plan to attempt across all countries.

\section{Mental disorders as risk factors}

In the cross-national sample, the presence of a prior mental disorder is associated with significantly increased risk of suicidal behaviours, even after controlling for socio-demographic factors, characteristics of suicidal behaviours, and country of residence (Tables 3 and 4). Relations are strongest across both high-, and low- and middle-income countries for mood disorders $(\mathrm{OR}=3.4-5.9)$ and impulse-control disorders $(\mathrm{OR}=3.3-6.5)$, followed by anxiety disorders $(\mathrm{OR}=2.8-4.8)$ and substance use disorders $(\mathrm{OR}=2.8-4.6)$. Importantly, associations between mental disorders and suicidal behaviours are attenuated when predicting plans and attempts among ideators, with ORs decreasing to $1.0-2.1$ across all categories. Among ideators, the risk of making an attempt is highest for those with substance use and impulsecontrol disorders, suggesting that these disorders are most strongly associated with acting on suicidal thoughts when they are present. Results also show a strong dose-response relationship between the number of mental disorders present and the risk of suicidal behaviours.

In within-country analyses, the presence of any mental disorder is associated with significantly increased risk in each of the 17 countries. The ORs for these analyses are quite stable, with only three countries differing significantly from the cross-national estimate for any outcome. Specifically, Israel is above the crossnational estimate for ideation, plan, and attempt, Italy is above the estimate for attempt, and Germany is below the estimate for ideation. The strong dose-response relationship between number 
Table 2 Socio-demographic risk factors for first onset of suicide-related outcomes among ideators: pooled analysis.

\begin{tabular}{|c|c|c|c|c|c|c|c|c|}
\hline \multirow[b]{2}{*}{ Socio-demographic factor } & \multicolumn{2}{|c|}{ Plan $(n=6872)^{\mathrm{a}}$} & \multicolumn{2}{|c|}{ Attempt $(n=6872)^{\mathrm{a}}$} & \multicolumn{2}{|c|}{$\begin{array}{l}\text { Attempt without a lifetime } \\
\text { plan }(n=4239)^{\mathrm{a}}\end{array}$} & \multicolumn{2}{|c|}{$\begin{array}{l}\text { Attempt with a lifetime plan } \\
\qquad(n=2633)^{\mathrm{b}}\end{array}$} \\
\hline & OR & $95 \% \mathrm{Cl}$ & OR & $95 \% \mathrm{Cl}$ & OR & $95 \% \mathrm{Cl}$ & OR & $95 \% \mathrm{Cl}$ \\
\hline \multicolumn{9}{|l|}{ Gender } \\
\hline Female & 1.1 & 1.0 to 1.3 & $1.3^{*}$ & 1.1 to 1.5 & $1.4^{*}$ & 1.1 to 1.7 & $1.3^{*}$ & 1.0 to 1.6 \\
\hline$\chi_{1}^{2}$ & 2.1 & & $12.6^{* *}$ & & $8.0^{* *}$ & & $5.3^{*}$ & \\
\hline \multicolumn{9}{|l|}{ Age, years ${ }^{c}$} \\
\hline $18-34$ & $1.4^{\star}$ & 1.0 to 1.9 & $1.8^{*}$ & 1.2 to 2.7 & $2.0^{*}$ & 1.1 to 3.6 & 1.6 & 0.9 to 2.7 \\
\hline $35-49$ & 1.2 & 0.9 to 1.7 & $1.8^{*}$ & 1.3 to 2.7 & $2.1^{*}$ & 1.2 to 3.7 & 1.6 & 0.9 to 2.7 \\
\hline $50-64$ & 1.2 & 0.9 to 1.5 & $1.6^{*}$ & 1.1 to 2.3 & $1.8^{*}$ & 1.0 to 3.2 & 1.5 & 0.9 to 2.5 \\
\hline$\chi_{3}^{2}$ & 4.5 & & $11.3^{\star \star}$ & & 7.6 & & 3.1 & \\
\hline \multicolumn{9}{|l|}{ Education $^{d}$} \\
\hline Student & 1.0 & 0.8 to 1.3 & 1.1 & 0.8 to 1.5 & 1.1 & 0.7 to 1.8 & 1.1 & 0.8 to 1.6 \\
\hline Low & 1.0 & 0.8 to 1.3 & $1.9 *$ & 1.4 to 2.5 & $2.2^{*}$ & 1.4 to 3.5 & $1.6^{*}$ & 1.1 to 2.4 \\
\hline Low/medium & 1.1 & 0.9 to 1.4 & $1.4^{*}$ & 1.1 to 1.9 & $1.6^{*}$ & 1.0 to 2.6 & 1.2 & 0.9 to 1.7 \\
\hline Medium & 1.1 & 0.9 to 1.4 & 1.3 & 1.0 to 1.7 & 1.6 & 1.0 to 2.5 & 1.1 & 0.8 to 1.5 \\
\hline$\chi_{4}^{2}$ & 1.9 & & $29.5^{\star *}$ & & $24.5^{\star *}$ & & $10.8^{*}$ & \\
\hline \multicolumn{9}{|l|}{ Ever employed } \\
\hline & 1.0 & 0.8 to 1.2 & 0.9 & 0.8 to 1.1 & 0.9 & 0.6 to 1.2 & 1.0 & 0.8 to 1.4 \\
\hline$\chi^{2} 1$ & 0.2 & & 0.6 & & 1.0 & & 0.1 & \\
\hline \multicolumn{9}{|l|}{ Ever married } \\
\hline No & 1.0 & 0.9 to 1.2 & 1.2 & 1.0 to 1.5 & 1.0 & 0.7 to 1.3 & 1.2 & 0.9 to 1.6 \\
\hline$\chi_{1}^{2}$ & 0.0 & & 2.9 & & 0.0 & & 2.0 & \\
\hline \multicolumn{9}{|l|}{ Age of onset of ideation ${ }^{\mathrm{e}}$} \\
\hline Early & $1.3^{*}$ & 1.0 to 1.6 & $2.2^{*}$ & 1.7 to 2.9 & $2.9^{*}$ & 1.9 to 4.4 & $1.8^{*}$ & 1.2 to 2.6 \\
\hline Middle & $1.2^{*}$ & 1.0 to 1.5 & $1.5^{\star}$ & 1.2 to 1.9 & $1.6^{*}$ & 1.1 to 2.2 & $1.5^{*}$ & 1.1 to 2.0 \\
\hline$\chi_{2}^{2}$ & 5.0 & & $32.2^{* *}$ & & $27.3^{\star *}$ & & $10.4^{* *}$ & \\
\hline \multicolumn{9}{|l|}{ Years since onset of ideation ${ }^{f}$} \\
\hline 0 & $117.4^{*}$ & 87.9 to 156.8 & $123.1^{*}$ & 92.9 to 162.9 & $174.6^{*}$ & 100.9 to 302.1 & - & - \\
\hline $1-5$ & $3.3^{*}$ & 2.4 to 4.5 & $4.4^{*}$ & 3.2 to 5.9 & $6.2^{\star}$ & 3.4 to 11.2 & - & - \\
\hline $6-10$ & $1.8^{*}$ & 1.2 to 2.6 & 1.5 & 1.0 to 2.1 & 1.5 & 0.6 to 3.4 & - & - \\
\hline$\chi_{3}^{2}$ & $2207.2^{* *}$ & & $2521.0^{* *}$ & & $873.6^{\star \star *}$ & & - & - \\
\hline \multicolumn{9}{|l|}{ Have a plan } \\
\hline Yes & - & - & $7.5^{\star}$ & 6.4 to 8.7 & - & - & - & - \\
\hline$\chi_{1}^{2}$ & - & - & $650.2^{* *}$ & & - & - & - & - \\
\hline \multicolumn{9}{|l|}{ Years since onset of plan ${ }^{f}$} \\
\hline 0 & - & - & - & - & - & - & $168.4^{*}$ & 106.6 to 266.1 \\
\hline $1-5$ & - & - & - & - & - & - & $5.0^{*}$ & 3.1 to 8.0 \\
\hline $6-10$ & - & - & - & - & - & - & 1.6 & 0.9 to 3.0 \\
\hline$\chi_{3}^{2}$ & - & - & - & - & - & - & $1126.1^{* *}$ & \\
\hline \multicolumn{9}{|c|}{$\begin{array}{l}\text { Results are based on multivariate discrete-time survival models with person-year as the unit of analysis; see the text for a description. -, indicates that the variable is not used as a } \\
\text { predictor in the model. } \\
\text { a. Model controls for years since onset of ideation. } \\
\text { b. Model controls for years since onset of plan. } \\
\text { c. Referent category: } 65+\text { years. } \\
\text { d. Referent category: high education. } \\
\text { e. Referent category: late. } \\
\text { f. Referent category: } 11+\text { years } \\
\star P<0.05 ; * \star P<0.01, \text { two-sided test. }\end{array}$} \\
\hline
\end{tabular}

of disorders and risk of suicidal behaviours is also consistent across all 17 countries.

Within-country analyses examining the relationship between each of the four disorder categories and the three primary suicidal behaviours also are largely consistent with those in the pooled cross-national sample, with only 3 of 204 ORs (1.5\%) less than 1.0 , and $92.5 \%$ of ORs significant at the 0.05 level. The greatest variability among countries is in the relation between mood disorder and suicidal behaviours. Seven countries have ORs significantly higher than the cross-national estimate (Belgium, China, Germany, Israel, Italy, Japan and Nigeria), with two countries (Colombia, France) below the cross-national estimate.

Analyses revealed an interesting pattern regarding low- and middle-income $v$. high-income countries. In high-income countries the presence of a mood disorder is the strongest predictor of suicidal ideation, plan and attempt (Table 3; 9 of 10 countries show this pattern). However, in low- and middle-income countries the presence of an impulse-control disorder is a stronger predictor than mood disorder (Table 4; 5 of the 6 countries in which impulse-control disorders were examined). Thus, although the presence of mental disorders in general, and comorbidity in particular, are consistently strong predictors of suicidal behaviours cross-nationally, there are notable differences in the type of disorder most strongly predictive of suicidal behaviours.

\section{Discussion}

The results of this study provide valuable and previously unavailable information about the prevalence and risk factors of suicidal behaviours around the world. Our results show that although there is substantial variability in the prevalence of suicidal behaviours cross-nationally, there are important cross-national consistencies in the prevalence and risk factors for suicidal behaviours. Most notably, across all countries examined, $60 \%$ of the transitions from suicidal ideation to first suicide attempt 
Table 3 High-income countries: DSM-IV disorders as risk factors for first onset of suicide-related outcomes (pooled analysis).

\begin{tabular}{|c|c|c|c|c|c|c|c|c|c|c|c|c|c|c|}
\hline \multirow[b]{3}{*}{ Disorder category } & \multicolumn{6}{|c|}{ Total sample ( $n=32$ 921) } & \multicolumn{8}{|c|}{ Among ideators } \\
\hline & \multicolumn{2}{|c|}{ Ideation } & \multicolumn{2}{|r|}{ Plan } & \multicolumn{2}{|c|}{ Attempt } & \multicolumn{2}{|c|}{$\begin{array}{c}\text { Plan } \\
(n=5017)\end{array}$} & \multicolumn{2}{|c|}{$\begin{array}{l}\text { Attempt } \\
(n=5017)\end{array}$} & \multicolumn{2}{|c|}{$\begin{array}{l}\text { Attempt without } \\
\text { a lifetime plan } \\
(n=3189)\end{array}$} & \multicolumn{2}{|c|}{$\begin{array}{l}\text { Attempt with } \\
\text { a lifetime plan } \\
(n=1828)\end{array}$} \\
\hline & OR & $95 \% \mathrm{Cl}$ & OR & $95 \% \mathrm{Cl}$ & OR & $95 \% \mathrm{Cl}$ & OR & $95 \% \mathrm{Cl}$ & OR & $95 \% \mathrm{Cl}$ & OR & $95 \% \mathrm{Cl}$ & OR & $95 \% \mathrm{Cl}$ \\
\hline $\begin{array}{l}\text { Any anxiety } \\
\text { disorders }^{\dagger, a}\end{array}$ & $3.4^{*}$ & 3.2 to 3.7 & $4.5^{\star}$ & 3.9 to 5.1 & $4.8^{*}$ & 4.1 to 5.5 & $1.6^{*}$ & 1.3 to 1.8 & $1.5^{\star}$ & 1.3 to 1.8 & $1.3^{*}$ & 1.0 to 1.7 & $1.6^{*}$ & 1.2 to 2.0 \\
\hline $\begin{array}{l}\text { Any mood } \\
\text { disorders } \$, a, b\end{array}$ & $4.7^{\star}$ & 4.2 to 5.2 & $5.8^{\star}$ & 4.9 to 6.9 & $5.9^{*}$ & 5.0 to 7.1 & $1.5^{\star}$ & 1.3 to 1.8 & $1.3^{*}$ & 1.1 to 1.6 & 1.3 & 0.9 to 1.7 & 1.2 & 0.9 to 1.5 \\
\hline $\begin{array}{l}\text { Any impulse- } \\
\text { control } \\
\text { disorders }^{\S, c}\end{array}$ & $3.3^{*}$ & 2.8 to 3.8 & $3.6^{*}$ & 2.8 to 4.6 & $4.2^{\star}$ & 3.3 to 5.4 & $1.4^{\star}$ & 1.0 to 1.9 & $1.5^{\star}$ & 1.1 to 2.1 & $1.5^{\star}$ & 1.0 to 2.3 & $1.5^{*}$ & 1.0 to 2.2 \\
\hline $\begin{array}{l}\text { Any substance } \\
\text { use disorders } \#, a, b\end{array}$ & $2.8^{*}$ & 2.5 to 3.2 & $4.1^{*}$ & 3.4 to 4.9 & $4.2^{\star}$ & 3.5 to 5.1 & $1.9^{*}$ & 1.6 to 2.4 & $1.6^{*}$ & 1.2 to 2.1 & $1.9^{*}$ & 1.3 to 2.7 & 1.4 & 1.0 to 1.9 \\
\hline Any disorders ${ }^{a}$ & $4.1^{\star}$ & 3.8 to 4.5 & $5.8^{\star}$ & 5.0 to 6.8 & $6.4^{*}$ & 5.4 to 7.6 & $1.6^{*}$ & 1.4 to 1.9 & $1.6^{*}$ & 1.3 to 1.9 & $1.5^{*}$ & 1.1 to 1.9 & $1.6^{*}$ & 1.2 to 2.1 \\
\hline $\begin{array}{l}\text { Exactly one } \\
\text { disorder }^{a}\end{array}$ & 1.0 & 0.9 to 1.1 & 0.9 & 0.7 to 1.1 & 0.8 & 0.7 to 1.1 & 0.8 & 0.6 to 1.0 & 0.8 & 0.6 to 1.1 & 0.7 & 0.4 to 1.1 & 0.9 & 0.6 to 1.3 \\
\hline $\begin{array}{l}\text { Exactly two } \\
\text { disorders }^{a}\end{array}$ & $2.1^{*}$ & 1.9 to 2.4 & $1.9^{*}$ & 1.5 to 2.2 & $1.9^{*}$ & 1.5 to 2.3 & 0.9 & 0.7 to 1.1 & 1.0 & 0.7 to 1.3 & 1.2 & 0.8 to 1.8 & 0.8 & 0.6 to 1.2 \\
\hline $\begin{array}{l}\text { Three or more } \\
\text { disorders }^{a}\end{array}$ & $6.1^{*}$ & 5.6 to 6.6 & $8.6^{*}$ & 7.4 to 10.0 & $8.9^{*}$ & 7.7 to 10.3 & $2.0^{*}$ & 1.7 to 2.4 & $1.8^{*}$ & 1.5 to 2.1 & $1.7^{*}$ & 1.3 to 2.1 & $1.8^{*}$ & 1.4 to 2.3 \\
\hline \multicolumn{15}{|c|}{$\begin{array}{l}\text { High-income countries include USA, Belgium, France, Germany, Italy, The Netherlands, Spain, Israel, Japan and New Zealand. Results are based on multivariate discrete-time survival } \\
\text { model. Each model controls for person-year, countries and the socio-demographic variables from Table } 1 . \\
{ }^{*} \text { Odds ratio (OR) significant at the } 0.05 \text { level, two-sided test. } \\
\text { †Panic, agoraphobia, generalised anxiety, specific phobia, social phobia, post-traumatic stress, and adult separation anxiety disorders. } \\
\text { "Major depressive, dysthymic, and bipolar disorders. } \\
\text { \$Intermittent explosive, attention-deficit/hyperactivity, conduct, and oppositional defiant disorders. } \\
\text { "Alcohol/illicit drug misuse or dependence. } \\
\text { a. Assessed in the Part II sample. } \\
\text { b. New Zealand assessed in the Part I sample. } \\
\text { c. Assessed only in the Part II sample with age range } 18-44 \text { years. }\end{array}$} \\
\hline
\end{tabular}

occurred within the first year of ideation onset. Moreover, consistent cross-national risk factors included female gender, younger age, fewer years of education, unmarried status and the presence of a mental disorder, with psychiatric comorbidity significantly increasing risk. Interestingly, the strongest diagnostic risk factors were mood disorders in high-income countries, but impulsecontrol disorders in low- and middle-income countries.

\section{Limitations}

Several important limitations should be borne in mind when interpreting these results. First, although the overall response rate was at an acceptable level, response rates varied across countries and in some cases were below commonly accepted standards. We controlled for differential response using post-stratification adjustments, but it is possible that response rates were related to the presence of suicidal behaviours or mental disorders, which could have biased cross-national comparisons. Also, although surveys in most countries included nationally representative samples, several surveys (e.g. China, Japan) focused on specific urban areas and so findings from those surveys may not generalise to all regions of those countries. A related limitation is that although we examined suicidal behaviours across 17 countries, several countries/regions with high rates of suicide, such as India and South East Asia, were not included. ${ }^{24}$ The inclusion of data from additional countries/regions in future work will significantly enhance our understanding of the factors influencing suicidal behaviours further.

Second, data were based on retrospective self-report of the occurrence and timing of suicidal behaviours, and thus may be subject to underreporting and biased recall. We also did not collect information from third-party informants to validate respondent reports. On balance, several systematic reviews have demonstrated that adults can recall past experiences with sufficient accuracy to provide valuable information, ${ }^{25,26}$ and such data are especially useful when prospective data are not available, ${ }^{27}$ as in the current case. Another limitation is that there may be cultural differences in the willingness to report on suicidal behaviours and in the interpretation of questions about DSM-IV mental disorders. Our results must be viewed with these limitations in mind.

Third, several mental disorders were not adequately assessed in the WMH surveys for various reasons. A few DSM-IV disorders were not assessed in some surveys because they were believed to have low relevance or they were excluded from analyses owing to an insufficient number of cases, such as impulse-control disorders in Nigeria. In some cases, disorders were not adequately assessed owing to skip logic errors, such as bipolar disorder and substance use disorders in the European Study of the Epidemiology of Mental Disorders surveys. ${ }^{10}$ Schizophrenia and other nonaffective psychoses were not included in any WMH survey because previous validation studies showed they are overestimated in lay-administered interviews like the CIDI. ${ }^{28}$ These exclusions are unfortunate because prior research clearly indicates that bipolar and substance use disorders are strongly associated with suicidal behaviours, ${ }^{3,6}$ suggesting that schizophrenia and suicidal behaviours share unique prevalence patterns and are strongly related in low- and middle-income countries; ${ }^{29}$ thus, the current study might have provided important information in this regard. The measurement of these disorders and the explanation of their relationship to suicidal behaviours in both high-income and low- and middle-income countries is one of the most important tasks for future work on this topic.

Fourth, this initial study included only a limited range of risk factors for suicidal behaviour. Factors such as individual Axis I and Axis II disorders, and traumatic life events were not examined 
Table 4 Low- and middle-income countries: DSM-IV disorders as risk factors for first onset of suicide-related outcomes (pooled analysis).

\begin{tabular}{|c|c|c|c|c|c|c|c|c|c|c|c|c|c|c|}
\hline \multirow[b]{3}{*}{ Disorder category } & \multicolumn{6}{|c|}{ Total sample $(n=15506)$} & \multicolumn{8}{|c|}{ Among ideators } \\
\hline & \multicolumn{2}{|c|}{ Ideation } & \multicolumn{2}{|c|}{ Plan } & \multicolumn{2}{|c|}{ Attempt } & \multicolumn{2}{|c|}{$\begin{array}{c}\text { Plan } \\
(n=1855)\end{array}$} & \multicolumn{2}{|c|}{$\begin{array}{l}\text { Attempt } \\
(n=1855)\end{array}$} & \multicolumn{2}{|c|}{$\begin{array}{l}\text { Attempt without } \\
\text { a lifetime plan } \\
\qquad(n=1050)\end{array}$} & \multicolumn{2}{|c|}{$\begin{array}{l}\text { Attempt with } \\
\text { a lifetime plan } \\
\quad(n=805)\end{array}$} \\
\hline & OR & $95 \% \mathrm{Cl}$ & OR & $95 \% \mathrm{Cl}$ & OR & $95 \% \mathrm{Cl}$ & OR & $95 \% \mathrm{Cl}$ & OR & $95 \% \mathrm{Cl}$ & OR & $95 \% \mathrm{Cl}$ & OR & $95 \% \mathrm{Cl}$ \\
\hline $\begin{array}{l}\text { Any anxiety } \\
\text { disorders } \\
\dagger, a\end{array}$ & $2.8^{*}$ & 2.4 to 3.2 & $3.6^{*}$ & 2.8 to 4.5 & $3.5^{\star}$ & 2.8 to 4.3 & $1.5^{*}$ & 1.2 to 1.9 & 1.2 & 0.9 to 1.5 & 1.1 & 0.7 to 1.6 & 1.3 & 0.9 to 1.8 \\
\hline $\begin{array}{l}\text { Any mood } \\
\text { disorders } \$ \text {,a }\end{array}$ & $3.4^{*}$ & 2.8 to 4.1 & $5.5^{*}$ & 4.4 to 6.9 & $4.7^{*}$ & 3.6 to 6.0 & $2.1^{*}$ & 1.6 to 2.9 & 1.0 & 0.8 to 1.4 & 0.8 & 0.5 to 1.3 & 1.2 & 0.8 to 1.9 \\
\hline $\begin{array}{l}\text { Any impulse- } \\
\text { control } \\
\text { disorders }^{\S, b}\end{array}$ & $4.4^{*}$ & 3.5 to 5.5 & $6.5^{*}$ & 4.8 to 8.8 & $6.3^{*}$ & 4.6 to 8.5 & $2.1^{*}$ & 1.5 to 2.9 & $1.6^{*}$ & 1.1 to 2.4 & 1.4 & 0.8 to 2.6 & $2.3^{*}$ & 1.3 to 4.2 \\
\hline $\begin{array}{l}\text { Any substance } \\
\text { use disorders }{ }^{\#, a}\end{array}$ & $2.9^{*}$ & 2.3 to 3.7 & $4.2^{*}$ & 3.0 to 5.9 & $4.6^{*}$ & 3.5 to 6.3 & $1.8^{*}$ & 1.1 to 2.8 & $1.4^{*}$ & 1.0 to 2.0 & 1.2 & 0.6 to 2.5 & 1.6 & 1.0 to 2.5 \\
\hline Any disorders ${ }^{a}$ & $3.6^{*}$ & 3.1 to 4.1 & $5.4^{*}$ & 4.4 to 6.7 & $5.3^{*}$ & 4.2 to 6.6 & $1.8^{*}$ & 1.4 to 2.4 & $1.4^{*}$ & 1.1 to 1.7 & 1.2 & 0.8 to 1.7 & $1.6^{*}$ & 1.1 to 2.3 \\
\hline $\begin{array}{l}\text { Exactly one } \\
\text { disorder }^{a}\end{array}$ & $1.4^{*}$ & 1.1 to 1.7 & 1.0 & 0.8 to 1.3 & 1.2 & 0.9 to 1.6 & $0.7^{*}$ & 0.5 to 1.0 & 0.9 & 0.7 to 1.3 & 0.9 & 0.5 to 1.6 & 1.0 & 0.6 to 1.6 \\
\hline $\begin{array}{l}\text { Exactly two } \\
\text { disorders }\end{array}$ & $2.8^{*}$ & 2.3 to 3.5 & $3.7^{*}$ & 2.9 to 4.7 & $3.1^{*}$ & 2.4 to 4.1 & $1.5^{*}$ & 1.1 to 2.1 & 1.1 & 0.8 to 1.6 & 0.9 & 0.5 to 1.5 & 1.0 & 0.6 to 1.7 \\
\hline $\begin{array}{l}\text { Three or more } \\
\text { disorders }^{a}\end{array}$ & $5.9^{*}$ & 4.9 to 7.2 & $10.0^{*}$ & 7.7 to 12.9 & $9.2^{*}$ & 7.4 to 11.6 & $2.5^{\star}$ & 1.9 to 3.3 & $1.5^{*}$ & 1.1 to 2.1 & $1.6^{*}$ & 1.0 to 2.6 & $1.8^{*}$ & 1.2 to 2.7 \\
\hline $\begin{array}{l}\text { Low- and middle-in } \\
\text { discrete-time surviva } \\
\text { *Odds ratio (OR) sig } \\
\text { †Panic, agoraphobia } \\
\text { "Major depressive, } \\
\text { \&Intermittent explosi } \\
\text { "Alcohol/illicit drug } \\
\text { a. Assessed in the P } \\
\text { b. Assessed only in }\end{array}$ & $\begin{array}{l}\text { me cou } \\
\text { model. } \\
\text { ficant at } \\
\text { senerali } \\
\text { sthymic } \\
\text {, attent } \\
\text { suse or } \\
\text { rt II sam } \\
\text { e Part I }\end{array}$ & $\begin{array}{l}\text { tries include } \\
\text { ach model co } \\
\text { the } 0.05 \text { level, } \\
\text { ed anxiety, sp } \\
\text { and bipolar di } \\
\text { on-deficit/hype } \\
\text { dependence. } \\
\text { le. } \\
\text { sample with a }\end{array}$ & $\begin{array}{l}\text { Colombi } \\
\text { ntrols fc } \\
\text { two-sid } \\
\text { ecific ph } \\
\text { isorders. } \\
\text { eractivity } \\
\text { ge rang }\end{array}$ & $\begin{array}{l}\text { a, Mexico, Ukra } \\
\text { r person-year, } \\
\text { led test. } \\
\text { lobia, social ph } \\
\text { l, conduct, and } \\
\text { e 18-44 years. }\end{array}$ & $\begin{array}{l}\text { obia, p } \\
\text { oppos }\end{array}$ & $\begin{array}{l}\text { anon, Nigeria, } \\
\text { s and the socic } \\
\text { it-traumatic str } \\
\text { onal defiant dis }\end{array}$ & $\begin{array}{l}\text { outh Afri } \\
\text { demogra } \\
\text { ss, and } \\
\text { rders. }\end{array}$ & $\begin{array}{l}\text { a and Peopl } \\
\text { phic variable }\end{array}$ & $\begin{array}{l}\text { Rep } \\
\text { from } \\
\text { anxie }\end{array}$ & $\begin{array}{l}\text { ic of China. } \\
\text { le } 1 . \\
\text { disorders. }\end{array}$ & ults & & & \\
\hline
\end{tabular}

in this study. Also excluded were potential protective factors such as treatment utilisation and social support. The investigation of these and other factors remain important directions for future research.

\section{Clinical implications and future research}

These limitations notwithstanding, several important findings from this study warrant more detailed comment. Perhaps the most important finding of this study is that there is strong cross-national consistency for several key risk factors for suicidal behaviours. Female gender, young age, and low educational attainment have been identified as risk factors for suicidal behaviours in prior studies, ${ }^{3,6}$ and the current findings suggest these risk factors may be universal. Future research is needed to determine whether risk of suicidal behaviours is occurring at higher rates among young people, or whether people simply become less likely to report on earlier suicidal behaviour with age, due to forgetting or re-interpretation of these earlier events.

Risk of suicide plans and attempts was also highest within the first year of ideation and when suicidal ideation had an earlier ageof-onset. Remarkably, $60 \%$ of the transitions from ideation to attempt - as well as from ideation to plan and plan to attempt - occur within the first year of onset of ideation and this result is consistent across all 17 countries. Few studies have examined the probability and speed of transition from ideation to plans and attempts, and this information can be especially useful to healthcare providers. Another important finding is that the strong relationship observed between mental disorders and suicide plans and attempts diminishes when controlling for ideation. Thus, although mental disorders are strong risk factors for suicidal behaviours, factors beyond the mere presence of mental disorders explain the transition from ideation to plans and attempts.
Several recent studies have suggested that mental disorders are less important in the occurrence of suicidal behaviours in low- and middle-income countries relative to high-income countries. Whereas studies in high-income countries suggest that $>90 \%$ of those who die by suicide have a diagnosable mental disorder and $>60 \%$ have a mood disorder in particular, ${ }^{30}$ rates in low- and middle-income countries have been suggested to be as low as $60 \%$ and $35 \%$ respectively. ${ }^{7}$ Our results indicate that when the same assessment methods are used cross-nationally, mental disorders are as predictive of suicidal behaviours in low- and middle-income countries as they are in high-income countries, and that comorbidity is an important predictor across all countries. Notably though, impulse-control disorders were stronger predictors than mood disorders in most low- and middle-income countries. The fact that mood and impulse-control disorders have the strongest associations with suicidal behaviours is consistent with prior work highlighting the importance of depressed mood and impulsiveness in the suicidal process, ${ }^{31}$ and extends these findings cross-nationally. The reason for the difference in the importance of impulse-control disorders between high-income and low- and middle-income countries is unclear and awaits further examination.

Future research must examine factors that might explain the variability in prevalence and must also develop more complex risk and protective models that take into account both common and specific factors for each country/region. From a practical perspective, the similarities observed between low- and middle-income and high-income countries suggest equivalent resources should be devoted to studying and preventing suicidal behaviours in these countries. Currently, resources devoted to the treatment of mental disorders in general, and to suicide prevention in particular, ${ }^{9}$ are lacking in many low- and middle-income (and high-income) countries. $^{7,10}$ It is important to note, however, that more 
treatment alone is not the answer. Several recent studies have highlighted that despite significant increases in service utilisation among suicidal individuals, the rates of suicidal ideation, plans and attempts have remained virtually unchanged. ${ }^{4}$ Moreover, although several different forms of treatment have proven effective at decreasing the likelihood of making suicide attempts, psychosocial treatments have proven less effective at decreasing the likelihood of death by suicide. ${ }^{32}$ Improvements in our ability to predict and prevent suicidal behaviours and suicide deaths are clearly needed, and require that we continue to identify the risk and protective factors that influence such behaviours. In addition, we need to develop more sophisticated methods for synthesising and using the information obtained about such factors.

Matthew K. Nock, PhD, Department of Psychology, Harvard University, Massachusetts, USA, Guilherme Borges, PhD, Department of Epidemiology, National Institute of Psychiatry and Universidad Autonoma Metropolitana, Mexico City, Mexico, Evelyn J. Bromet, PhD, Department of Psychiatry, State University of New York Stony Brook, USA, Jordi Alonso, MD, PhD, Health Services Research Unit, Institut Municipal d'Investigacio Medica IMIM, Barcelona, Spain, Matthias Angermeyer, MD, University of Leipzig, Department of Psychiatry, Leipzig, Germany, Annette Beautrais, PhD, Christchurch School of Medicine \& Health Sciences, New Zealand, Ronny Bruffaerts, PhD, Department of Neurosciences and Psychiatry, University Hospitals, Gasthuisberg, Belgium, Wai Tat Chiu, AM, Department of Health Care Policy, Harvard Medical School, Boston, Massachusetts, USA, Giovanni de Girolamo, MD, Department of Mental Health, AUSL di Bologna, Bologna, Italy, Semyon Gluzman, MD, Ukrainian Psychiatric Association, Kyiv, Ukraine, Ron de Graaf, PhD, Netherlands Institute of Mental Health and Addiction, Utrecht, The Netherlands, Oye Gureje, MD, PhD, FRCPsych, Department of Psychiatry, University College Hospital, Ibadan, Nigeria, Josep Maria Haro, MD, MPH, PhD, Sant Joan de Deu-SSM, Barcelona, Spain, Yueqin Huang, MPH, MD, PhD, Institute of Mental Health, Peking University, People's Republic of China, Elie Karam, MD, Department of Psychiatry and Psychology, St George Hospital University Medical Center, Beirut, Lebanon, Ronald C. Kessler, PhD, Department of Psychology, Harvard University, Massachusetts, USA, Jean Pierre Lepine MD, Hospital Fernand Widal, Paris, France, Daphna Levinson, PhD, Research and Planning Mental Health Services, Ministry of Daphna Levinson, PhD, Research and Planning, Mental Health Services, Min
Health, Jerusalem, Israel, Maria Elena Medina-Mora, PhD, Department of Health, Jerusalem, Israel, Maria Elena Medina-Mora, PhD, Department
Epidemiology, National Institute of Psychiatry and Universidad Autonoma Metropolitana, Mexico City, Mexico, Yutaka Ono, MD, Keio University, Tokyo, Japan, José Posada-Villa, MD, Colegio Mayor de Cundinamarca University, Saldarriaga Concha Foundation, Bogota, Colombia, David Williams, PhD, MPH, Harvard University School of Public Health, Boston, Massachusetts, USA.

Correspondence: Matthew K. Nock, PhD, Department of Psychology, Harvard University, 33 Kirkland Street, 1280 Cambridge, MA 02138, USA. Email: nock@wjh.harvard.edu

First received 7 May 2007, final revision 7 Oct 2007, accepted 27 Nov 2007

\section{Acknowledgements}

The surveys included in this report were carried out in conjunction with the World Health Organization WHO World Mental Health (WMH) Survey Initiative. We thank the WMH staff for assistance with instrumentation, fieldwork, and data analysis. These activities were supported by the United States National Institute of Mental Health (NIMH; R01MH077883, R01MH070884), the John D. and Catherine T. MacArthur Foundation, the Pfizer Foundation, the US Public Health Service (R13-MH066849, R01-MH069864, and R01 DA016558), the Fogarty International Center (FIRCA R01-TW006481), the Pan American Health Organization (PAHO), Eli Lilly, Ortho-MCNeil Pharmaceutical, GlaxoSmithKline, and Bristol-Myers Squibb. A complete list of WMH publications can be found at http://www.hcp.med.harvard.edu/wmh/ The Chinese World Mental Health Survey Initiative is supported by the Pfizer Foundation. The Colombian National Study of Mental Health is supported by the Ministry of Socia Protection, with supplemental support from the Saldarriaga Concha Foundation. The European Study of the Epidemiology of mental Disorders project is funded by the European Commission (contracts QLG5-1999-01042; SANCO 2004123), the Piedmont Region, Italy, Fondo de Investigación Sanitaria, Instituto de Salud Carlos III, Spain FIS 00/0028, Ministerio de Ciencia y Tecnología, Spain (SAF 2000-158-CE), Departament de Salut, Generalitat de Catalunya, Spain (RETICS RD06/0011 REM-TAP Network), and other local agencies and by an unrestricted educational grant from GlaxoSmithKline. The Israel National Health Survey is funded by the Ministry of Health with support from the Israel National Institute for Health Policy and Health Services Research and the National Insurance Institute of Israel. The World Mental Health Japan Survey is supported by the Grant for Research on Psychiatric and Neurological Diseases and Mental Health (H13-SHOGAl-023, H14-TOKUBETSU 026. H16-KOKORO-013) from the Japan Ministry of Health, Labour and Welfare. The Lebanese National Mental Health Survey is supported by the Lebanese Ministry of Public Health, the WHO (Lebanon), the Fogarty International Center and anonymous private donations to Institute for Development, Research, Advocacy and Applied Care, Lebanon and unrestricted grants from Janssen Cilag, Eli Lilly, GlaxoSmithKline, Roche, and Novartis. The Mexican National Comorbidity Survey is supported by The National Institute of Psychiatry Ramon de la Fuente (INPRFMDIES 4280) and by the National Council on Science and Technology (CONACYT-G30544-H), with supplemental support from the PAHO. Te Rau Hinengaro: The New Zealand Mental Health Survey is supported by the New Zealand Ministry of Health, Alcohol Advisory Council, and the Health Research Council. The Nigerian Survey of Mental Health and Wellbeing is supported by the WHO (Geneva and Nigeria) and the Federal Ministry of Health, Abuja, Nigeria. The South Africa Stress and Health Study is supported by the US NIMH (R01-MH059575) and National Institute of Drug Abuse (NIDA) with supplemental funding from the South African Department of Health and the University of Michigan. The Ukraine Comorbid Mental Disorders during Periods of Social Disruption study is funded by the US NIMH (RO1-MH61905). The US National Comorbidity Survey Replication is supported by the NIMH (U01-MH60220) with supplemental support from the NIDA, the Substance Abuse and Mental Health Services Administration, the Robert Wood Johnson Foundation (grant 044708), and the John W. Alden Trust. R.C.K., as principa investigator, had full access to all of the data in the study and takes responsibility for the integrity of the data and the accuracy of the data analysis.

\section{References}

1 World Health Organization. Prevention of Suicide: Guidelines for the Formulation and Implementation of National Strategies. World Health Organization, 1996

2 Vijayakumar L, Nagaraj K, Pirkis J, Whiteford H. Suicide in developing countries 1: frequency, distribution, and association with socioeconomic indicators. Crisis 2005; 26: 104-11.

3 Moscicki EK. Epidemiology of suicide. In The Harvard Medical School Guide to Suicide Assessment and Intervention (ed D.G. Jacobs): 40-51. Jossey-Bass, 1999.

4 Kessler RC, Berglund P, Borges G, Nock MK, Wang PS. Trends in suicide ideation, plans, gestures, and attempts in the United States, 1990-1992 to 2001-2003. J Am Med Assoc 2005; 293: 2487-95

5 Weissman MM, Bland RC, Canino GJ, Greenwald S, Hwu HG, Joyce PR, Karam EG, Lee CK, Lellouch J, Lepine JP, Newman SC, Rubio-Stipec M, Wells JE, Wickramaratne PJ, Wittchen HU, Yeh EK. Prevalence of suicide ideation and suicide attempts in nine countries. Psychol Med 1999; 29: 9-17.

6 Kessler RC, Borges G, Walters EE. Prevalence of and risk factors for lifetime suicide attempts in the National Comorbidity Survey. Arch Gen Psychiatry 1999; 56: 617-26.

7 Vijayakumar L. Suicide prevention: the urgent need in developing countries World Psychiatry 2004; 3: 158-9.

8 Phillips MR, Yang G, Zhang Y, Wang L, Ji H, Zhou M. Risk factors for suicide in China: a national case-control psychological autopsy study. Lancet 2002; 360: $1728-36$.

9 Mann JJ, Apter A, Bertolote J, Beautrais A, Currier D, Haas A, Hegerl U, Lonnqvist J, Malone K, Marusic A, Mehlum L, Patton G, Phillips M, Rutz W, Rihmer Z, Schmidtke A, Shaffer D, Silverman M, Takahashi $Y$, Varnik A Wasserman $D$, Yip $P$, Hendin $H$. Suicide prevention strategies: a systematic review. J Am Med Assoc 2005; 294: 2064-74.

10 Demyttenaere K, Bruffaerts R, Posada-Villa J, Gasquet I, Kovess V, Lepine JP, Angermeyer MC, Bernert S, de Girolamo G, Morosini P, Polidori G, Kikkawa T, Kawakami N, Ono Y, Takeshima T, Uda H, Karam EG, Fayyad JA, Karam AN, Mneimneh ZN, Medina-Mora ME, Borges G, Lara C, de Graaf R, Ormel J, Gureje $\mathrm{O}$, Shen $\mathrm{Y}$, Huang $\mathrm{Y}$, Zhang M, Alonso J, Haro JM, Vilagut G, Bromet EJ, Gluzman S, Webb C, Kessler RC, Merikangas KR, Anthony JC, Von Korff MR, Wang PS, Brugha TS, Aguilar-Gaxiola S, Lee S, Heeringa S, Pennell BE, Zaslavsky AM, Ustun TB, Chatterji S; on behalf of the WHO World Mental Health Survey Consortium. Prevalence, severity, and unmet need for treatment of mental disorders in the World Health Organization World Menta Health Surveys. JAMA 2004; 291: 2581-90.

11 Platt S, Bille-Brahe U, Kerkhof $A$, Schmidtke A, Bjerke T, Crepet $P$, De Leo D, Haring C, Lonnqvist J, Michel K, Philippe A, Pommereau X, Querejeta I, Salander-Renberg E, Temesvary B, Wasserman D, Sampaio Faria J. Parasuicide in Europe: the WHO/EURO multicentre study on parasuicide. I. Introduction and preliminary analysis for 1989. Acta Psychiatr Scand 1992; 85: $97-104$.

12 Bertolote JM, Fleischmann A, De Leo D, Bolhari J, Botega N, De Silva D, Tran Thi Thanh $H$, Phillips $M$, Schlebusch L, Värnik A, Vijayakumar L, Wasserman D. Suicide attempts, plans, and ideation in culturally diverse sites: the WHO SUPRE-MISS community survey. Psychol Med 2005; 35: 1457-65.

13 Alonso J, Angermeyer MC, Bernert S, Bruffaerts R, Brugha TS, Bryson $\mathrm{H}$, de Girolamo G, Graaf R, Demyttenaere K, Gasquet I, Haro JM, Katz SJ, Kessler RC, Kovess V, Lépine JP, Ormel J, Polidori G, Russo L, Vilagut G, Almansa J, Arbabzadeh-Bouchez S, Autonell J, Bernal M, Buist-Bouwman MA, Codony M, Domingo-Salvany $A$, Ferrer $M$, Joo SS, Martínez-Alonso $M$, Matschinger $\mathrm{H}_{\text {, }}$ Mazzi F, Morgan Z, Morosini P, Palacín C, Romera B, Taub N, Vollebergh WA on behalf of the ESEMED/MHEDEA 2000 Investigators, European Study of the Epidemiology of Mental Disorders ESEMeD Project. Sampling and methods of the European Study of the Epidemiology of Mental Disorders (ESEMeD) project. Acta Psychiatr Scand Suppl 2004; 420: 8-20.

14 World Bank. World Development Indicators 2003. The World Bank, 2003.

15 Kessler RC, Merikangas KR. The National Comorbidity Survey Replication (NCS-R): background and aims. Int J Methods Psychiatr Res 2004; 13: 60-8. 
16 Kessler RC, Ustun TB. The World Mental Health (WMH) Survey Initiative Version of the World Health Organization (WHO) Composite International Diagnostic Interview (CIDI). Int J Methods Psychiatr Res 2004; 13: 93-121.

17 Turner CF, Ku L, Rogers SM, Lindberg LD, Pleck JH, Sonenstein FL. Adolescent sexual behaviour, drug use, and violence: increased reporting with computer survey technology. Science 1998; 280: 867-73.

18 First MB, Spitzer RL, Gibbon M, Williams JBW. Structured Clinical Interview for DSM-IV-TR Axis I Disorders, Research Version, Non-Patient Edition (SCID-I/ NP). Biometrics Research, New York State Psychiatric Institute, 2002.

19 Kessler RC, Berglund P, Demler O, Jin R, Walters EE. Lifetime prevalence and age-of-onset distributions of DSM-IV disorders in the National Comorbidity Survey Replication. Arch Gen Psychiatry 2005; 62: 593-602.

20 Haro JM, Arbabzadeh-Bouchez S, Brugha TS, de Girolamo G, Guyer ME, Jin R, Lepine JP, Mazzi F, Reneses B, Vilagut G, Sampson NA, Kessler RC. Concordance of the Composite International Diagnostic Interview Version 3.0 (CIDI 3.0) with standardized clinical assessments in the WHO World Mental Health Surveys. Int J Methods Psychiatr Res 2006; 15: 167-180.

21 Efron B. Logistic regression, survival analysis, and the Kaplan Meier curve. $J$ Am Sociol Assoc 1988; 83: 414-25.

22 Wolter K. Introduction to Variance Estimation. Springer-Verlag, 1985.

23 SUDAAN: Professional Software for Survey Data Analysis computer program. 8.0.1 Version. Research Triangle Institute, 2002.

24 Eddleston M, Konradsen F. Commentary: time for a re-assessment of the incidence of intentional and unintentional injury in India and South East Asia. Int J Epidemiol 2007; 36: 208-11.
25 Brewin CR, Andrews B, Gotlib IH. Psychopathology and early experience: a reappraisal of retrospective reports. Psychol Bull 1993; 113: 82-98.

26 Hardt J, Rutter M. Validity of adult retrospective reports of adverse childhood experiences: review of the evidence. J Child Psychol Psychiatry 2004; 45: 260-73.

27 Schlesselman JJ. Case-Control Studies: Design, Conduct, and Analysis Oxford University Press, 1982.

28 Kendler KS, Gallagher TJ, Abelson JM, Kessler RC. Lifetime prevalence, demographic risk factors, and diagnostic validity of nonaffective psychosis as assessed in a US community sample. The National Comorbidity Survey. Arch Gen Psychiatry 1996; 53: 1022-31.

29 Phillips MR, Yang G, Li S, Li Y. Suicide and the unique prevalence pattern of schizophrenia in mainland China: a retrospective observational study. Lancet 2004; 364: 1062-8.

30 Cavanagh JT, Carson AJ, Sharpe M, Lawrie SM. Psychological autopsy studies of suicide: a systematic review. Psychol Med 2003; 33: 395-405.

31 Mann JJ, Waternaux C, Haas GL, Malone KM. Toward a clinical model of suicidal behaviour in psychiatric patients. Am J Psychiatry 1999; 156: 181-9.

32 Crawford MJ, Thomas O, Khan N, Kulinskaya E. Psychosocial interventions following self-harm: systematic review of their efficacy in preventing suicide. Br J Psychiatry 2007; 190: 11-7.

क EXTRA

\section{Word pictures of depression: anhedonia} Sharon Mcconville

I have never been a particularly hedonistic type of person, but for me, the following illustration is useful in summing up my experience of anhedonia:

'The sun is shining brilliantly and the sky is a cloudless azure. Everything looks pristine. The trees and bushes appear velvety, like model vegetation on a model railway set, and the lines of the buildings are sharp like the edges of neatly-wrapped parcels. My friends are excited because they have planned to watch a movie which is being projected on to the cliff face at Cavehill, and it is a perfect evening for such an adventure. I have a ticket but I have decided not to go. It is cloudy and dark in my inner world and I do not have the energy left to construct a bridge which I can cross into this bright parallel reality. Sometimes I can do it; sometimes I can mentally detach myself from the gloom and live for a time in the glow created by the people around me, like a candle which does not quite smoulder out because it is relit using the flame of others which burn more strongly. This is an excursion which I would ordinarily enjoy: the film is one which I would like to see; the people are friends with whom I am comfortable; I would like to be outside in a beautiful setting with panoramic views; and the novelty value of marrying Hollywood commercialism with the stark majesty of nature appeals to me. Tonight, I know that I could not concentrate on any film; I am intimidated by the thought of having to interact with a number of different people, taking into account their different needs and the differing expectations which they have of me; and I crave silence and space unmarred by noisy crowds.' 